Femtosecond laser writing of waveguide structures in sodium calcium silicate glasses

W. J. Reichman, C. A. Click, D. M. Krol

January 20, 2005

Photonics West

San Jose, CA, United States

January 22, 2005 through January 27, 2005 
This document was prepared as an account of work sponsored by an agency of the United States Government. Neither the United States Government nor the University of California nor any of their employees, makes any warranty, express or implied, or assumes any legal liability or responsibility for the accuracy, completeness, or usefulness of any information, apparatus, product, or process disclosed, or represents that its use would not infringe privately owned rights. Reference herein to any specific commercial product, process, or service by trade name, trademark, manufacturer, or otherwise, does not necessarily constitute or imply its endorsement, recommendation, or favoring by the United States Government or the University of California. The views and opinions of authors expressed herein do not necessarily state or reflect those of the United States Government or the University of California, and shall not be used for advertising or product endorsement purposes. 


\title{
Femtosecond laser writing of waveguide structures in sodium calcium silicate glasses
}

\author{
W. Reichman ${ }^{1,2}$, C. A. Click ${ }^{3}$, and D. M. Krol ${ }^{1,2}$ \\ ${ }^{1}$ Department of Applied Science, University of California, Davis, CA 95616, USA \\ ${ }^{2}$ Lawrence Livermore National Laboratory, 7000 East Ave, Livermore, CA 94550, USA \\ ${ }^{3}$ Schott North America, Inc., 400 York Ave., Duryea, PA 18642, USA
}

\begin{abstract}
Waveguides were written in soda lime silicate glasses with a composition of $\mathrm{xNa}_{2} \mathrm{O} \times \mathrm{CaO}(1-2 \mathrm{x}) \mathrm{SiO}_{2}$, where $\mathrm{x}=15$ and 20, using an amplified femtosecond laser. The waveguides formed around, not inside the exposed regions. This is similar to the waveguide behavior our group first observed in a phosphate glass, Schott IOG-1, and is distinctly different from fused silica in which the waveguides are inside the exposed regions. This data supports the rapid quenching theory, i.e. that the exposed regions cool rapidly, locking in a glass structure with a high fictive temperature, with the dependence of the refractive index on the glass cooling rate determining the qualitative behavior of the waveguides.
\end{abstract}

Keywords: Femtosecond Laser Modification, Fused Silica, Soda Lime Silicate

\section{INTRODUCTION}

Localized refractive index changes can be induced in transparent glass using femtosecond (fs) laser pulses. Waveguide structures can be fabricated inside bulk glass by tightly focusing the laser inside the glass and scanning the glass with respect to the laser focus, [1-7]. This technique holds tremendous potential as a fabrication technique for three dimensional all-optical integrated components with applications in telecommunications as well as in biological and chemical sensors and medical technology. The mechanism of ultrashort-laser-pulse modification of transparent materials can be divided into the absorption and dissipation of the laser's energy. The energy absorption process is fairly well understood [8-12], however, many questions remain concerning the nature of the plasma created and the energy dissipation process(es) [13]:

The energy absorption process is normally divided into three steps. First, several electrons are promoted to the conduction band through multiphoton absorption. Multiphoton absorption is a process in which several photons are absorbed simultaneously to excite an electron in materials that have too large of a band-gap for linear absorption to occur (transparent materials). Second, more electrons are promoted to the conduction band through avalanche photoionization. Once an electron has been excited to the conduction band it can linearly absorb photons through inverse Bremsstrahlung absorption [11]. When an electron with more energy than the band gap collides with another bound electron, it can promote the second electron to the conduction band. This cycle is repeated resulting in a rapid increase in the concentration of conduction electrons. Third, when a sufficient number of electrons have been excited, a plasma forms [12].

After the plasma forms, it is less certain how the energy dissipates. Two mechanisms are believed to dissipate most of the energy: shockwave propagation (micro-explosion) or thermal diffusion. The shockwave theory states that the plasma expands rapidly creating a pressure wave that travels through the material [13]. The thermal diffusion theory states that the heat is bled away through conduction within the material [1]. It is not certain which mechanism is dominant, or if the dominant mechanism is a function of writing conditions. Either way, the end result of these steps are localized physical, chemical, and structural changes, such as densification, refractive index changes, and/or color center formation, of the material after exposure to the laser beam.

Waveguide fabrication using femtosecond laser pulses has been most thoroughly studied in fused silica. It is known that a refractive index increase of $\sim 10^{-4}$ can be induced in fused silica using "moderate" laser powers with less power resulting in no visible modification and more power resulting in damage lines that scatter light [14]. Exact power levels 
are highly dependent on the laser pulse width, and focusing conditions. The localized index increase has been used to fabricate waveguides (figure 1, left) and various other optical devices.

Work on waveguides written in Schott IOG -1, a phosphate glass, using a focused fs laser has shown that the guiding behavior is qualitatively different than the guiding behavior observed in fused silica. Waveguides in IOG-1 guide around the modified region with the exact structure being highly dependent on the laser alignment during fabrication; in contrast waveguides in fused silica guide within the modified region (figure 1). This behavior indicates that femtosecond laser modification results in a higher refractive index in fused silica, and a lower refractive index in IOG-1 [15] within the exposed region. One way to explain this difference is that the plasma cools rapidly, irrespective of cooling method, freezing the material in the same structure it had at high temperature. This is referred to as the rapid quenching model. It is known that rapidly quenched bulk fused silica is known to have a higher refractive index [16, 17], and rapidly quenched bulk IOG -1 was measured to have a lower refractive index [15]. Unfortunately, there are many other differences between fused silica and IOG-1 that could affect waveguide formation, the foremost of these being that silicate and phosphate glasses have very different microstructures.
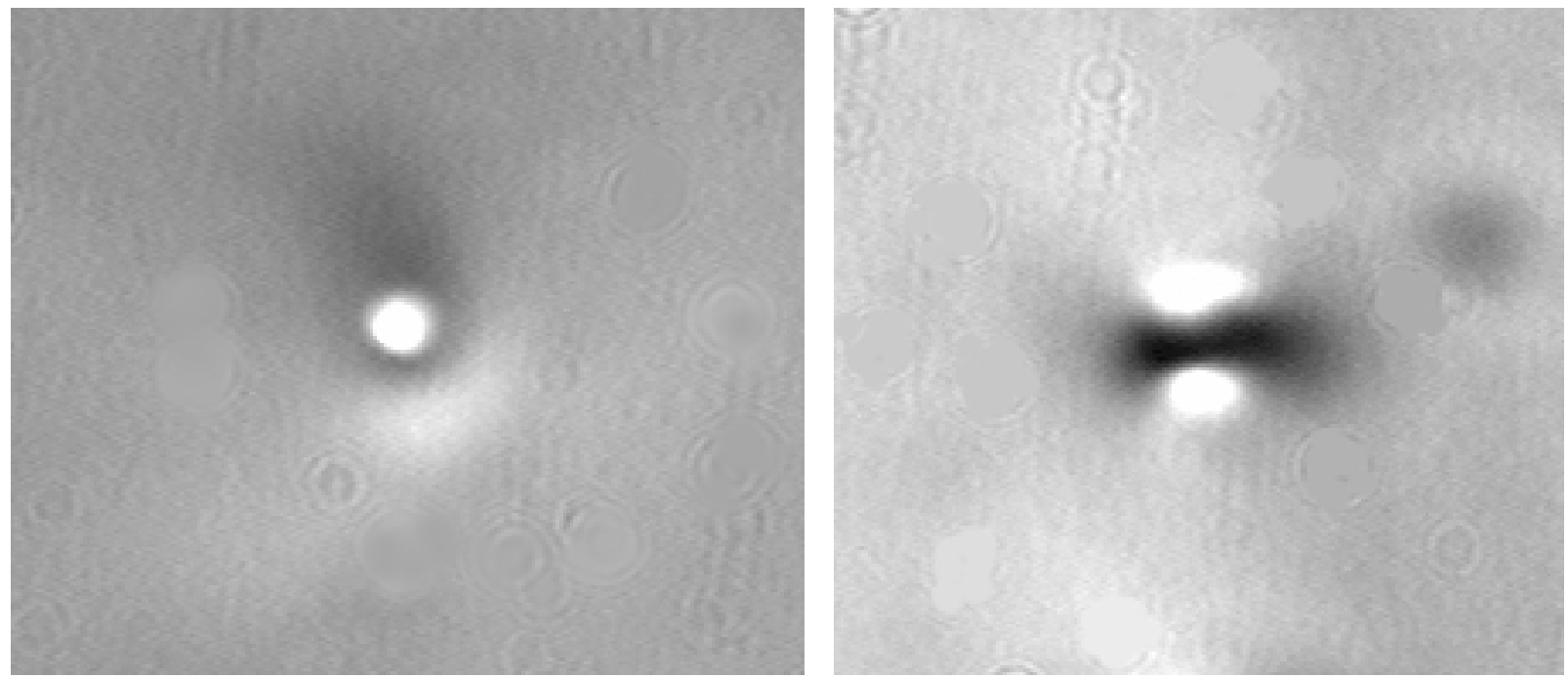

Figure 1. White light images of waveguides in fused silica (left), and IOG-1 (right).

Our current study is designed to test the rapid quenching theory by systematically examining the waveguiding behavior of soda lime silicate glasses in the $\mathrm{xNa}_{2} \mathrm{O} \mathrm{xCaO}(1-2 \mathrm{x}) \mathrm{SiO}_{2}$ series. It is known that rapid quenching of glasses with high alkali content will result in a lower refractive index [18], similar to IOG. By observing the type of waveguides produced and comparing this to the relationship between cooling rate and refractive index at various values of $\mathrm{x}$, it should be possible to determine if the rapid quenching theory is valid. In addition, we will use spectroscopy to examine the local microstructure changes that occur within the glasses.

\section{EXPERIMENTAL DETAILS}

The glasses studied are Corning 7940 type III silica glass (fused silica), Schott Company Glass $6\left(15 \mathrm{Na}_{2} \mathrm{O} 15 \mathrm{CaO}\right.$ $\left.70 \mathrm{SiO}_{2}\right)$, and Schott Company Glass $4-2\left(20 \mathrm{Na}_{2} \mathrm{O} 20 \mathrm{CaO} 60 \mathrm{SiO}_{2}\right)$. A combined microscope system, shown in figure 2, was used to fabricate the waveguides, test the waveguide coupling behavior, and perform Raman and fluorescence spectroscopy without physically removing the sample. To fabricate the waveguides a Ti-sapphire laser operating at $800 \mathrm{~nm}$ with a 130 fs pulse width, and a $1 \mathrm{kHz}$ repetition rate was focused through a Nikon 20X 0.4 NA ELWD objective using pulse energies from 0.15 to $20 \mu \mathrm{J}$ after the objective. A half wave plate on a rotation mount followed by a polarized beam splitter was used to adjust the power. The sample was moved at $20 \mu \mathrm{m} \mathrm{s}^{-1}$, parallel to the laser beam to create the modified lines. Care was taken to ensure that the focal spot never reached the sample surface. 


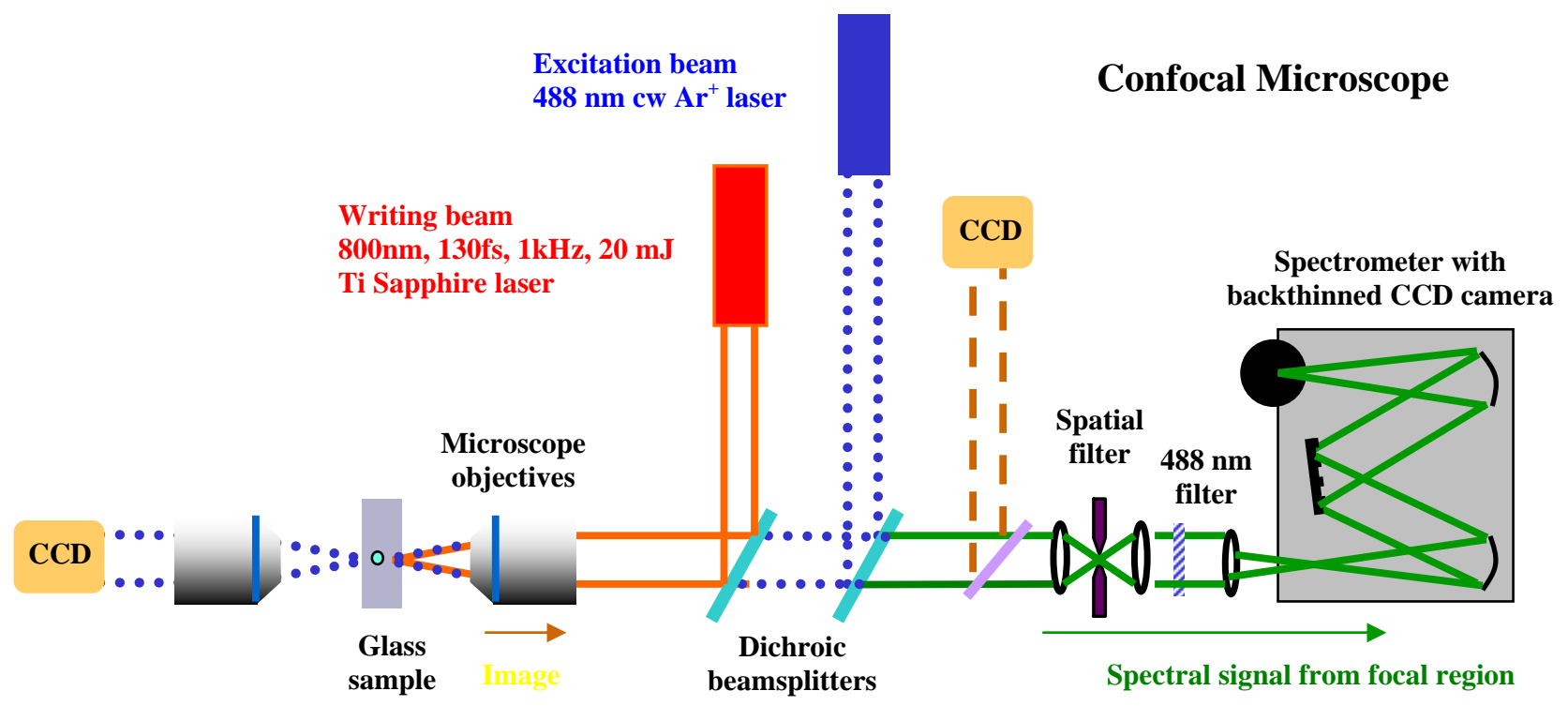

Figure 2. Schematic diagram of the combined fs laser writing and scanning confocal microscope setup.

After fabricating the waveguides a 488nm Ar ion laser, set to low power $(5 \mathrm{~mW})$, was coupled into the resulting waveguides by adjusting either the 5 -axis stage the sample was mounted on, or the 3 -axis stage supporting the $1^{\text {st }}$ microscope objective. The far field image was observed on a screen 70" from the sample, and the near field image was collected using a $2^{\text {nd }}$ microscope objective and a CCD camera as shown in figure 2. Spectroscopy was performed by increasing the Ar ion laser power to $50 \mathrm{~mW}$, and collecting the back scattered / emitted light using a confocal microscope. The confocal microscope uses a $75 \mu \mathrm{m}$ pinhole between two $150 \mathrm{~mm}$ achromatic doublet lenses as a spatial filter, a $488 \mathrm{~nm}$ long-pass filter to eliminate the excitation laser, and either a Perkin Elmer MP-942 photomultiplier tube (PMT) or an Oriel MS 257 spectrometer with a Roper 100B liquid nitrogen cooled CCD camera to collect the light. The PMT is used to rapidly measure the total scattering and emission from the sample as a function of spatial position with an acquisition time of $0.1 \mathrm{~s}$ per point. The spectrometer is used to measure changes in the fluorescence spectra as a function of spatial position with an acquisition time of $5 \mathrm{~min}$ per point. A 300 groove per $\mathrm{mm}$ $500 \mathrm{~nm}$ blaze grating was used for fluorescence spectroscopy.

\section{RESULTS \& DISCUSSION}
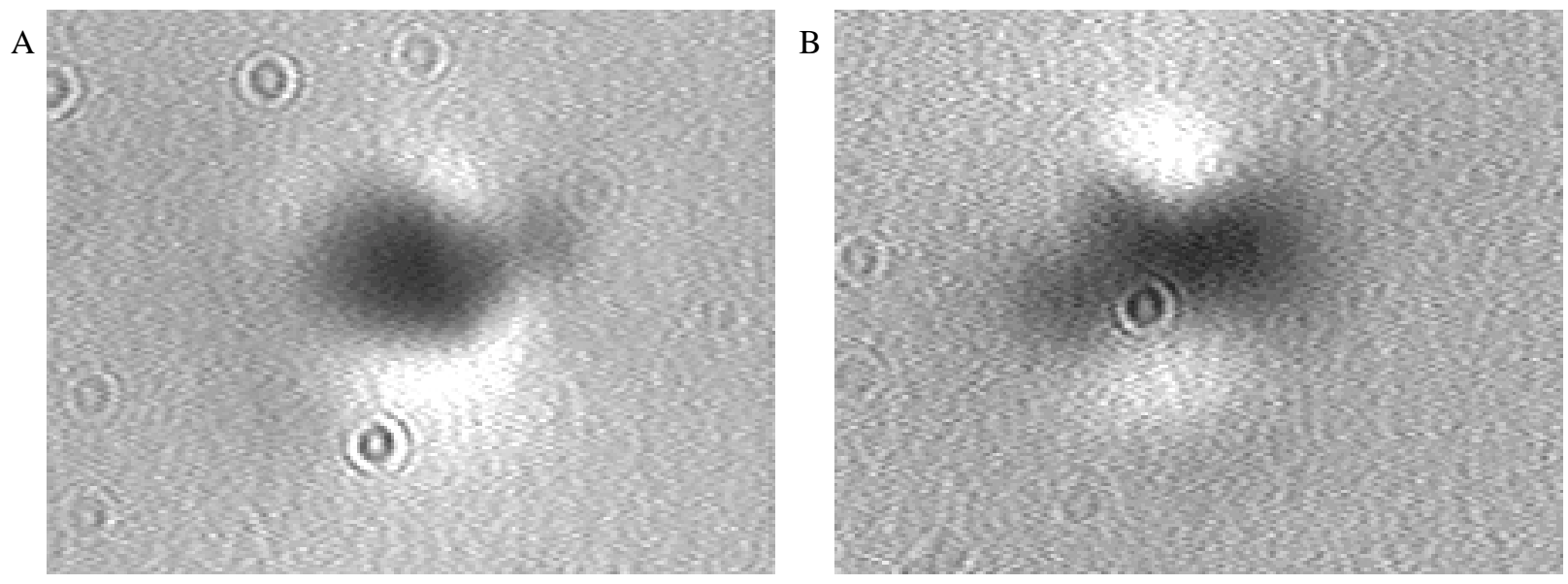

Figure 3. A) White light images of the endfaces of a $9.3 \mu \mathrm{J}$ line in $15 \mathrm{Na}_{2} \mathrm{O} 15 \mathrm{Ca} 2 \mathrm{O} 70 \mathrm{SiO}_{2}$, and $\left.\mathrm{B}\right) 20 \mathrm{Na}_{2} \mathrm{O} 20 \mathrm{CaO} 60 \mathrm{SiO}{ }_{2}$ 
A

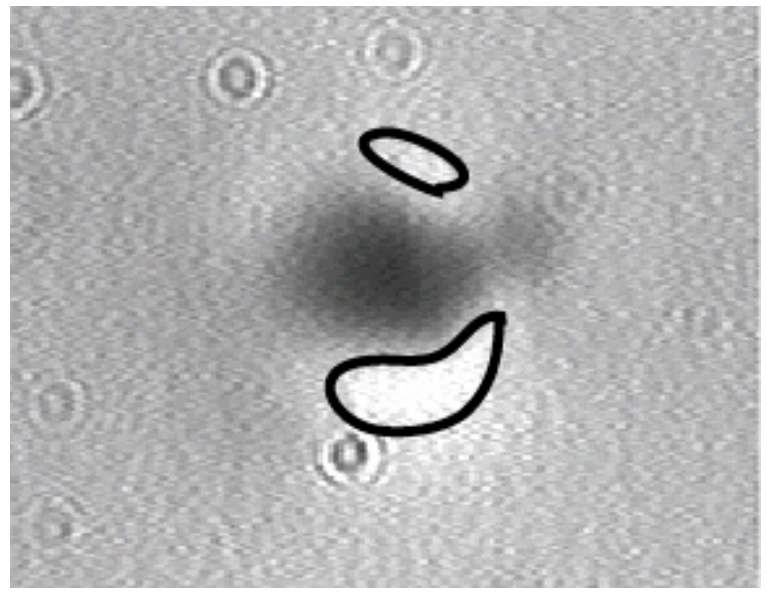

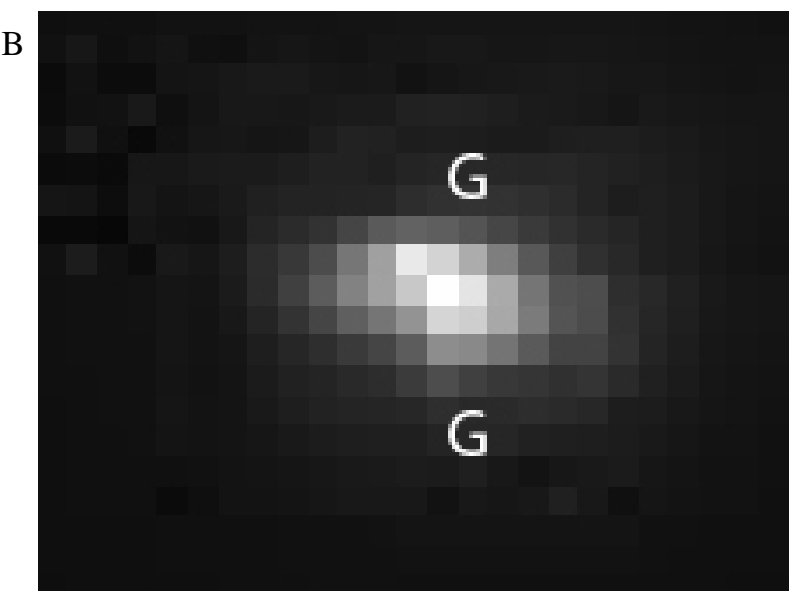

Figure 4. A) White light image and B) fluorescence image of the endface of a $9.3 \mu \mathrm{J}$ line in $15 \mathrm{Na}_{2} \mathrm{O} 15 \mathrm{Ca} 2 \mathrm{O} 70 \mathrm{SiO}_{2}$. The black circles in the white light image, and the " $G$ "s in the fluorescence image denote where waveguide coupling was achieved.

Figure 3 shows the white light images of waveguides in both of the soda lime silicate glasses. The waveguide behavior is similar to the behavior of IOG-1, shown in figure 1. There is a non-guiding central region that appears black, bounded by guiding peripheral regions that appear white in the white light images. This pattern is observed for all lines that exhibit guiding behavior. It was found that a wide range of laser pulse energies produced such waveguides in both soda lime silicate samples. Lines created with 5 to $10 \mu \mathrm{J}$ pulse energies had regions with good guiding behavior. Lines created with more power exhibit a larger black damaged region, without the white guiding peripheral regions. Lines created with less power appear as dull grey ellipses that fade to invisibility with pulse energies less than $0.25 \mu \mathrm{J}$. This is different from fused silica in which the lowest power lines that are visible are also waveguides.

Figures $4 \mathrm{~A}$ and $4 \mathrm{~B}$ show a white light image and cross-section image of the total emission intensity of the same waveguide shown in figure 3A under identical magnification. Each pixel in the fluorescence image is $0.5 \mu \mathrm{m}$. By comparing this image with the coordinates where waveguide coupling is possible we can determine that guiding takes place in regions (marked with "G") on either side of the exposed central region, from which the fluorescence is

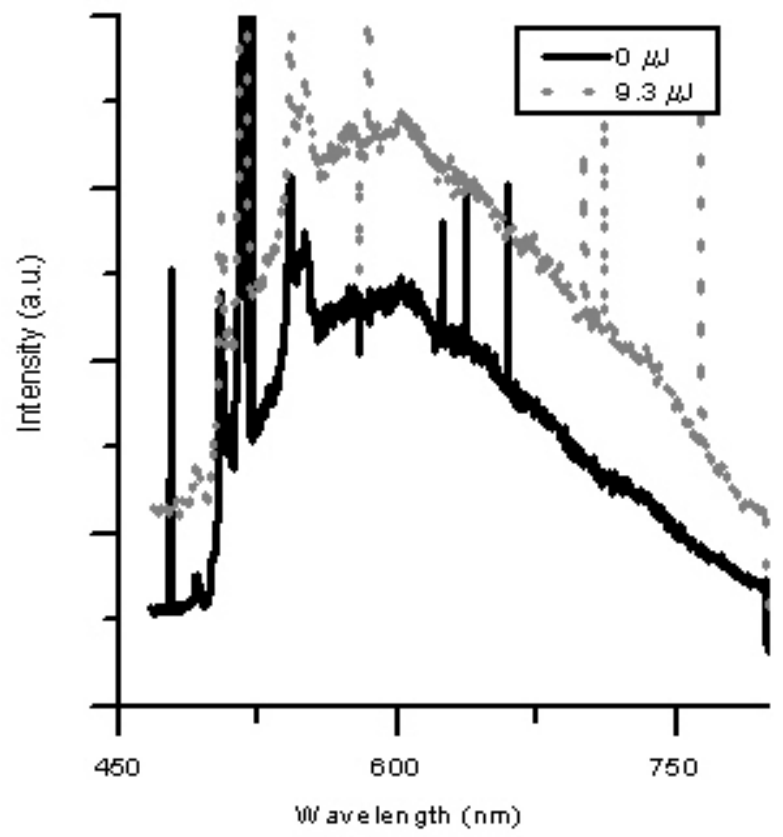

Figure 5. Fluorescence spectra of a $9.3 \mu \mathrm{J}$ line, and unmodified glass in $15 \mathrm{Na}_{2} \mathrm{O} 15 \mathrm{Ca} 2 \mathrm{O} 70 \mathrm{SiO}_{2}$. 

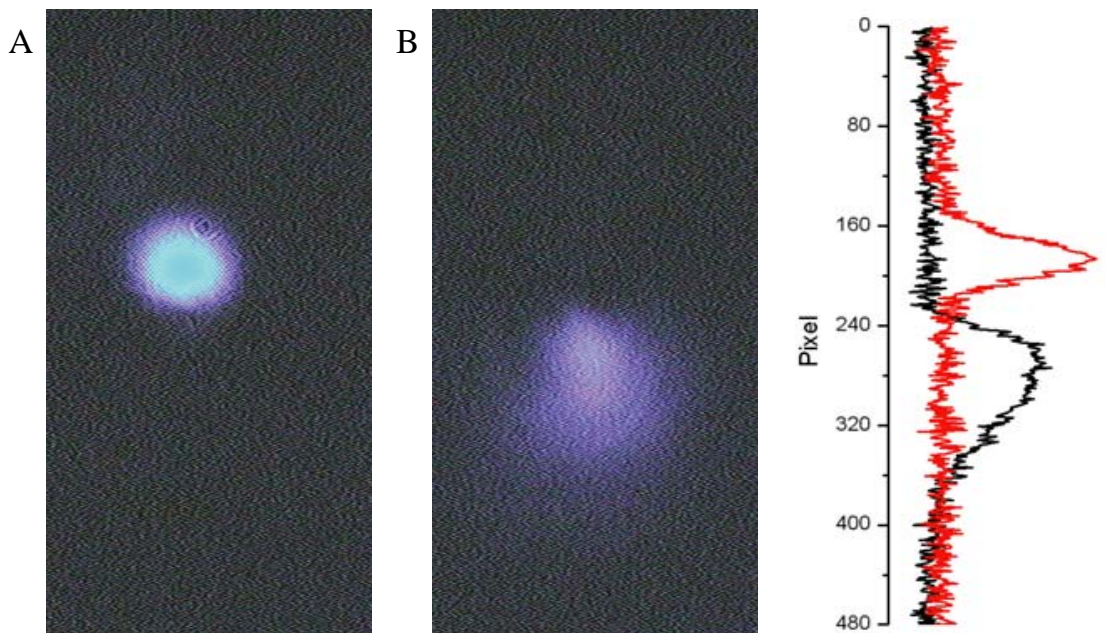

Figure 6. Near field profiles of $9.3 \mu \mathrm{J}$ waveguides A) above the modified region, and B) below the modified region in $15 \mathrm{Na}_{2} \mathrm{O} 15 \mathrm{CaO} 70 \mathrm{SiO}_{2}$ glass and the intensity distribution.
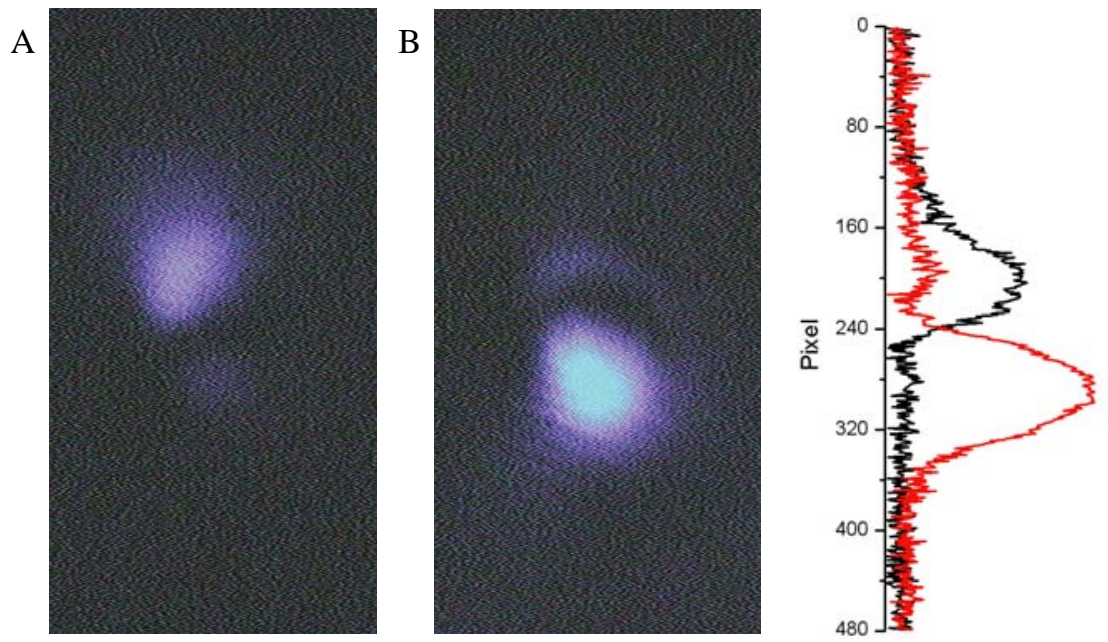

Figure 7. Near field profiles of $9.3 \mu \mathrm{J}$ waveguides A) above the modified region, and B) below the modified region in $20 \mathrm{Na}_{2} \mathrm{O} 20 \mathrm{CaO} 60 \mathrm{SiO}_{2}$ glass and the intensity distribution.

observed. Spectroscopy was used to determine the nature of the modified region's emission. Spectra of the center of the exposed region and of unmodified glass are shown in figure 5. A broad (increase in the) fluorescence centered around $610 \mathrm{~nm}$ is observed for the modified region. This fluorescence band is due to NBOHC defects that are formed in the region exposed to the fs laser. The contrast between modified and unmodified regions is less pronounced in the fluorescence spectra (figure 5) than in the fluorescence image (figure 4B) because of photobleaching that occurs during the spectra's longer acquisition time. Similar photobleaching of NBOHC defects has been observed in fused silica [14].

Near field images were collected for each guiding region to evaluate the waveguide quality. Figure 6 shows that for the $15 \mathrm{Na}_{2} \mathrm{O} 15 \mathrm{CaO} 70 \mathrm{SiO}_{2}$ sample, there is very nice, almost circular, guiding behavior in the upper waveguide. The lower waveguide is far more diffuse and elongated to one side. The $20 \mathrm{Na}_{2} \mathrm{O} 20 \mathrm{CaO} 60 \mathrm{SiO}_{2}$ sample (figure 7) shows the opposite behavior with better confinement in the lower waveguide than in the upper, with both profiles being slightly elongated. This difference is a result of minor positioning adjustments of the writing beam passing through the objective. Note, for comparing figures 4 and 6 it is necessary to invert the images because of the second microscope objective used to collect the near field profiles.

The near field profiles are arranged as a function of writing energy in figure 8. Higher powers gave rise to excessive scattering resulting in no well defined waveguides. Some guiding was evident at lower powers between 1.5 and $5 \mu \mathrm{J}$, 


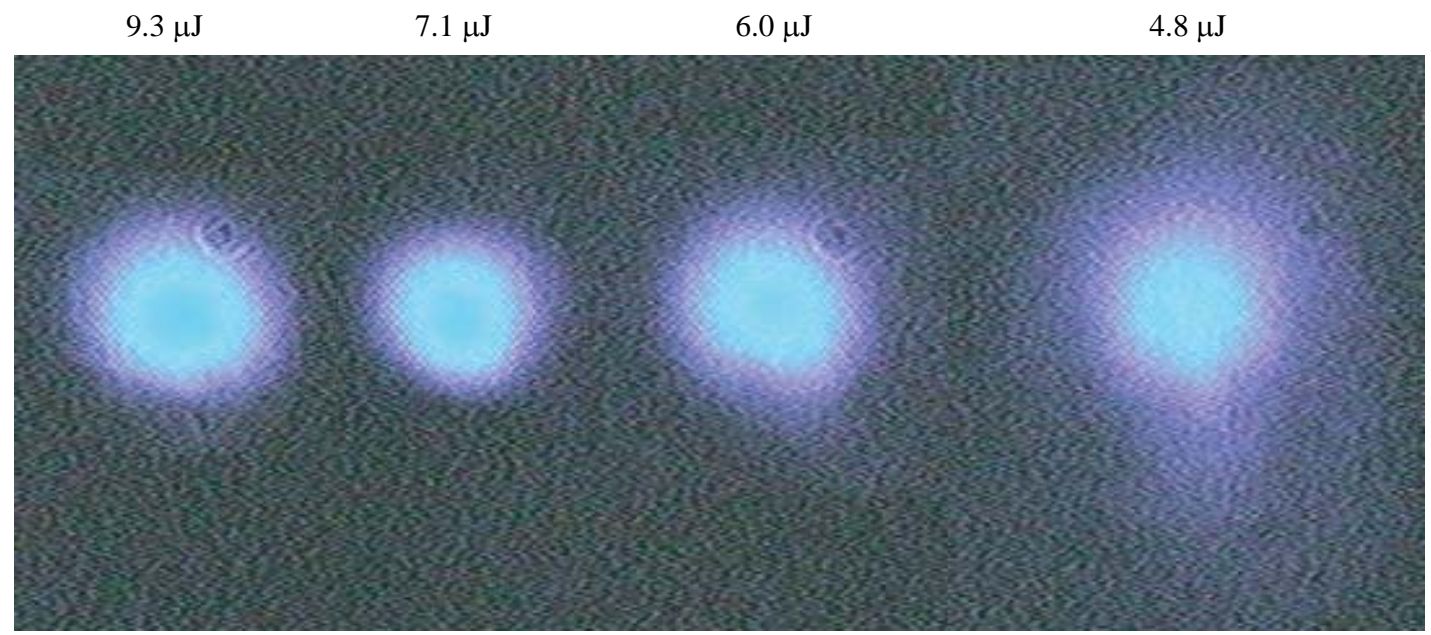

Figure 8. Composite image of the near field profiles of “top" waveguides in $15 \mathrm{Na}_{2} \mathrm{O} 15 \mathrm{CaO} 70 \mathrm{SiO}_{2}$ glass.

however, the spot size rapidly increased indicating poor beam confinement. It is our belief that while some modification clearly occurred, the refractive index change induced is not sufficient to produce good quality waveguides.

The far-field profiles were used to calculate approximate values for the refractive index by calculating the NA of the spreading cone, and comparing this value to the theoretical NA for total internal reflection of a step index change, using equations 1 and 2 respectively,

$$
\begin{gathered}
N A \sim \tan (\theta)=\frac{d}{2 z} \\
N A=\sqrt{2 n_{o} \Delta n}
\end{gathered}
$$

where $\mathrm{d}$ is the far-field waveguide diameter, $\mathrm{z}$ is the distance over which the far-field profiles were measured (70"), $\mathrm{n}_{\mathrm{o}}$ is the refractive index of the unmodified glass, and $\Delta \mathrm{n}$ is the change in the refractive index. Equation 1 assumes $\mathrm{d}<<2 \mathrm{z}$, and equation 2 assumes $\Delta \mathrm{n}<<\mathrm{n}_{0}$.

All of the waveguides had $\Delta \mathrm{n}$ values within a factor of 4 of $10^{-4}$. No significant trends were observed between the refractive index change and the writing power, though this may be due to large errors in the far-field measurements.

Taken together these results clearly show that waveguides written in soda lime silicate glasses $\left(15 \mathrm{Na}_{2} \mathrm{O} 15 \mathrm{CaO} 70 \mathrm{SiO}_{2}\right.$ and $20 \mathrm{Na}_{2} \mathrm{O} 20 \mathrm{CaO} 60 \mathrm{SiO}_{2}$ ) guide around the modified region. This is similar to the behavior observed in IOG-1, and supports the rapid quenching theory of waveguide formation because both the soda lime silicate glasses and IOG-1 have a lower bulk refractive index with increased quenching rate. Additional samples with smaller alkali content are currently being studied in an attempt to determine at what composition waveguides change from IOG-1 like behavior to fused silica like behavior. If this behavioral change coincides with a change in the relationship between refractive index versus cooling rate it will strongly support the rapid quenching theory.

\section{SUMMARY}

Waveguides were fabricated in soda lime silicate glasses with compositions of $\mathrm{xNa}_{2} \mathrm{O} \mathrm{xCaO}(1-2 \mathrm{x}) \mathrm{SiO}_{2}$ where $\mathrm{x}=15$, and 20. The resulting waveguides exhibit the same behavior our group first observed in IOG-1 glass; the waveguides are around but not within a central modified line. This result has been confirmed using white light imaging, fluorescence imaging, and by measuring the near field profiles of the waveguides. Both the soda lime silicate glasses, and IOG-1 have a lower bulk refractive index with increased quenching rate, supporting the fast quenching theory for femtosecond laser waveguide fabrication. 


\section{ACKNOWLEDGMENTS}

This work was performed under the auspices of the US Department of Energy by the University of California Lawrence Livermore National Laboratory, through M Division within Physics and Applied Technology, under contract W-7405Eng-48, UCRL-PROC-209130. The authors acknowledge financial support through National Science Foundation grant DMR - 0307002.

\section{REFERENCES}

[1] Davis KM,Miura K, Sugimoto N and Hirao K, "Writing waveguides in glass with a femtosecond laser,” Opt. Lett., 21 1729-31, 1996.

[2] Miura K, Qiu J R, Inouye H, Mitsuyu T and Hirao K, "Photowritten optical waveguides in various glasses with ultrashort pulse laser,” Appl. Phys. Lett., 71 3329-31, 1997.

[3] Hirao K and Miura K, "Writing waveguides and gratings in silica and related materials by a femtosecond laser," $J$. Non-Cryst. Solids, 239 91-5, 1998.

[4] Schaffer C B, Brodeur A, Garcia J F and Mazur E, "Micromachining bulk glass by use of femtosecond laser pulses with nanojoule energy,” Opt. Lett., 26 93-5, 2001.

[5] Homoelle D, Wielandy S, Gaeta A L, Borrelli N F and Smith C, "Infrared photosensitivity in silica glasses exposed to femtosecond laser pulses," Opt. Lett., 24 1311-13, 1999.

[6] Efimov OM, Glebov L B, Richardson K A, Van Stryland E, Cardinal T, Park S H, CouziMand Bruneel J L, "Waveguide writing in chalcogenide glasses by a train of femtosecond laser pulses," Opt. Mater., 17 379-86, 2001.

[7] Miura K, Jianrong Q, MitsuyuT and Hirao K, "Preparation and optical properties of fluoride glasswaveguides induced by laser pulses,” J. Non-Cryst. Solids, 257 212-19, 1999.

[8] Jones S C, Braunlich P, Casper R T, Shen X A and Kelly P, "Recent progress on laser-induced modifications and intrinsic bulk damage of wide-gap optical-materials," Opt. Eng., 28 1039-68, 1989.

[9] Schaffer C B, Brodeur A and Mazur E, "Laser-induced breakdown and damage in bulk transparent materials induced by tightly focused femtosecond laser pulses,” Meas. Sci. Technol., 12 1784-94, 2001.

[10] Liu X, Du D and Mourou G, "Laser ablation and micromachining with ultrashort laser pulses," IEEE J. Quantum Electron. 33, 1706-16, 1997.

[11] Stuart B C, FeitMD, Herman S, Rubenchik A M, Shore BWand Perry MD, "Nanosecond-to-femtosecond laserinduced breakdown in dielectrics,” Phys. Rev. B, 53 1749-61, 1996.

[12] Du D, Liu X, Korn G, Squier J and Mourou G, "Laser-induced breakdown by impact ionization in SiO2 with pulse widths from 7 ns to 150 fs,” Appl. Phys. Lett., 64 3071-3, 1994.

[13] Glezer E N and Mazur E, "Ultrafast-laser driven micro-explosions in transparent materials,” Appl. Phys. Lett., 71 882-4, 1997.

[14] Chan JW, Huser T R, Risbud S H and Krol D M, "Modification of the fused silica glass network associated with waveguide fabrication using femtosecond laser pulses,” Appl. Phys. A, 76 367-72, 2003.

[15] Chan J W, Huser T R, Risbud S H, Hayden J S, Krol D M, "Waveguide fabrication in phosphate glasses using femtosecond laser pulses,” Appl. Phys. Lett., 82 2371-3, 2003.

[16] Haken U, Humbach O, Ortner S, Fabian H, "Refractive index of silica glass: influence of fictive temperature," J. of Non-Crystalline Solids, 265 9-18, 2000.

[17] Bruckner R, “Properties and Structure of Vitreous Silica. I,” J. of Non-Crystalline Solids, 5 123-175, 1970.

[18] Scholze H, Glass: Nature, Structure, and Properties, New York State College of Ceramics, Alfred, NY, pp 211, 1991. 